vida de Lina será interpretar y entregar secretos parciales, hasta llegar a la muerte con el confuso recuerdo del salón de los espejos, creyendo percibir su significado (p. 190), pero callándolo para siempre.

La novela deja muchos hilos por tejer, para lecturas futuras. Un significativo aporte es la recuperación de un mundo femenino semitransgresor, que transmite oral y gestualmente las tretas del débil y enseña, así, a sobrevivir en vidas dobles, matando, poseyendo, anestesiándose y obteniendo placeres tan parciales y dudosos que sólo denuncian su real ineficacia. Como tantas obras de la historia de la literatura, En diciembre llegaban las brisas gusta porque no puede gustar. No hay paz, ni complacencias, ni salidas. La primera lectura no es fácil ni dulce. Al fin y al cabo, cuando llegan las brisas, muy cerca del mar, el único sabor que queda, pegajoso, es el de la sal. Lamer la sal, antiguo rito bautismal, puede ser un paso hacia la sabiduría.

Universidad de los Andes, Bogotá.

MONTSERRAT ORDÓÑEZ

Susana Reisz de Rivarola, Teoria literaria. Una propuesta. Lima: Fondo Editorial, Pontificia Universidad Católica del Perú, 1986.

Esta obra de la investigadora argentina implica un notable esfuerzo de su parte por crear un libro de teoría literaria que sea a un tiempo un tratado introductorio a la disciplina y una puesta al día de sus problemas, vistos a la luz de la moderna teoría del texto y de la pragmática. La profesora Reisz de Rivarola procedió a estudiar cada problema con espíritu crítico científico, discutiendo exhaustivamente a los autores más destacados que lo han investigado y luego presentando su propia posición con rigor metodológico. Logra así introducir al lector en una compleja bibliografía especializada; algunos de estos autores, como Schmidt, Glinz, Gumbrecht, Landwehr, Stierle, Schemme, Schulte-Sasse, Waldmann, en su mayoría no traducidos al español, muestran el desarrollo crítico de los investigadores alemanes representantes de la teoría del texto, cuyos estudios en los Estados Unidos circulan casi exclusivamente dentro de los grupos especializados en lingüística y son poco conocidos por los hispanistas dedicados al estudio práctico de autores y problemas literarios de su disciplina; además de estos investigadores, Reisz discute aquellos otros considerados «clásicos» dentro de los estudios literarios actuales, y mucho más difundidos, como Genette, Todorov, Greimas, Van Dijk, Lotman; también considera los trabajos de Walter Mignolo, un hispanista que ha contribuido al estudio de la textualidad y la teoría literaria.

En el primer capítulo, una introducción convencional y didáctica trata de revisar las definiciones de literatura que dieron en el pasado otros tratadistas de teoría literaria como Wellek y V. M. de Aguiar e Silva. El libro empieza realmente en el segundo capítulo, cuando la autora define y describe lo que es para ella un sistema literario; su definición trata de llegar a una síntesis estructural-funcional, y la noción de texto tiene un papel decisivo al iluminar las relaciones que se dan dentro del acto de comunicación literaria, de una manera que, a fuerza de ser rigurosamente lógica, se vuelve algo mecánica, pero muestra bien la conexión entre las partes, sus rasgos distintivos, y plantea problemas fundamentales, como el de la competencia lingüística y literaria. En el tercer capítulo la autora analiza la relación entre literatura y poesía, y es este último el modo literario más exhaustivamente 
considerado en su libro; cree que Jakobson, en su definición de «función poética», no ha tomado en cuenta «ni la situación comunicativa ni los códigos extralingüísticos puestos en juego por los comunicantes» (p. 64). Reisz insiste en que la lírica es antidiscurso y transgresión (p. 69), noción negativa y, a mi juicio, poco convincente que sostuvieron también en el pasado teóricos como Jean Cohen y Riffaterre, aunque trata de incorporar a la misma un aspecto positivo: el de la capacidad informativa intensificada que adquiere el texto poético al relacionarse simultáneamente con varios contextos.

En el cuarto capítulo analiza el problema de la lectura y la situación evaluativa que se suscita como consecuencia del acto de leer; ilustra con ejemplos los tipos posibles de lectura, pero dada la complejidad del tema abordado, me parece que el tratamiento es algo superficial; la forma en que considera el tema del «desgaste del lenguaje», aspecto nunca visto con mucha claridad por la teoría literaria, es insuficiente; lo mismo ocurre en el capítulo quinto, en donde estudia la literatura "trivial» o de consumo, porque la teoría del texto, que es más efectiva cuanto más estructuralmente complejo es el problema estudiado, se vuelve reiterativa y simplificadora cuando tiene que explicar las literaturas de masas, que presentan más problemas semánticos y sociológicos que formales. Su tratamiento posterior de los géneros literarios le permite una investigación más satisfactoria para el lector; Reisz discute, con buen conocimiento filológico, la clasificación de géneros, remontándose con justicia a Platón y Aristóteles, y propone una revisión de esta clasificación apoyándose en el juicio de Stierle, que refuerza su opinión de que la lírica es un género transgresivo, un antigénero; yo creo que Reisz, en esta parte, no hace una diferencia satisfactoria entre los géneros literarios, por un lado, y prosa y poesía como modos literarios, por el otro, y características esencialmente históricas como la asociación casi permanente de lírica y verso se le aparecen como una propiedad genérica. En los capítulos siete y ocho estudia el problema de lo ficcional dentro de lo literario; estos dos capítulos son la mayor aportación de la profesora Reisz a la teoría literaria, por tratarse de un problema poco estudiado y por el estudio minucioso a que somete el tema; discute, con rigor, la teoría ficcional aristotélica y los componentes del mundo ficcional. Critica la noción de lo fantástico de Todorov, prefiriendo la noción de Bessière de «posible», «imposible», que, a mi parecer, tampoco resuelve todos los problemas de mímesis o representación que suscita la poética de lo fantástico. Analiza la relación entre poesía y ficción, considerando, con gran lucidez, el problema del yo lírico y el "hermetismo» en poesía; aquí la teoría del texto aclara realmente la naturaleza de los enunciados poéticos. Entiendo que la teoría sobre la ficción de la autora presenta un punto débil: su definición insatisfactoria de «realidad», basada en Glinz (p. 144), que no toma en cuenta la construcción de la noción de realidad de la poética del realismo literario; a partir de esa omisión, la autora tiene que derivar en su teoría de lo posible/imposible, viciada de un psicologismo que repite el mismo error que trata de subsanar en Todorov, apartándose de su mismo objetivo funcional-estructural dentro del cual quería estudiar lo literario.

La Teoría literaria de Reisz de Rivarola es un estudio rico y complejo, un esfuerzo intelectual sostenido y satisfactorio que hace una verdadera aportación a la materia que estudia. Al enfrentarse a un tratado de esta naturaleza, el lector debe tener en cuenta que es prácticamente imposible responder satisfactoriamente a todos los problemas que plantea la literatura, por lo que es esencial considerar al crítico por la riqueza de su enfoque y su habilidad para abrir el campo de estudio a nuevos interrogantes; la profesora Reisz demuestra ser una investigadora que conoce 
muy bien el tema, lo presenta de manera interesante y con gran claridad conceptual, posee conocimientos amplios de diversas disciplinas, de la lingüística a la estética, $\mathrm{y}$ ha logrado sintetizar bien desde el punto de vista literario las contribuciones que la teoría del texto ha hecho a nuestra disciplina, en especial a la crítica literaria.

\section{Dartmouth College}

Alberto Julián Pérez

Alicia Colombí Monguió, Petrarquismo peruano: Diego Dávalos y Figueroa y la poesía de la «Miscelánea Austral». London: Tamesis Books Limited, 1985.

Como observa la autora en el «Prólogo» de este libro, la historia de la lírica hispanoamericana de los siglos XVI y xvIr todavía ofrece a los investigadores un campo poco menos que virgen, sobre todo en lo que respecta a edición de textos, algunos manuscritos, que se guardan en bibliotecas de España, Inglaterra, etc. Esa labor de exhumación y exégesis crítica está siendo cumplida, con ejemplar seriedad, por una pléyade de profesores dedicados a la literatura del período colonial que enseñan en universidades de América y Europa, bien conocidos y apreciados por los especialistas. Ya hay números de la Revista Iberoamericana dedicados exclusiva o parcialmente a las letras del que yo prefiero llamar "período hispánico», porque no fue sólo colonización y trasplante, sino recreación de la herencia española, enriquecida con elementos novomundanos y la aportación clásica revitalizada y universalizada por el Renacimiento italiano.

En la poesía que se produjo en la América hispánica, sobre todo en el siglo XVI, junto a la muy hispánica de cancioneros, romanceros, coplas y otras formas de invención y repetición populares, la línea cultista de procedencia petrarquesca y, en general, italo-renacentista es la que predomina en las compilaciones de florilegios colectivos o misceláneas compuestas por un solo autor, ya anónimo, ya conocido, como son los casos de la Miscelánea Antártica, El Marañón, el Parnaso Antártico y la Miscelánea Austral, por sólo mencionar el legado más notable de la actividad poética de la Nueva Castilla (véase información panorámica en mi libro En este aire de América, México, 1966, pp. 67-80). Y no podemos dudar hoy, ante la extraordinaria aportación de Alicia Colombí Monguió, que «con las Flores de Baria Poesía compiladas en México (habría que agregar, también de la Nueva España, la Silva de poesía, compuesta por Eugenio Salazar..., que hemos estudiado en nuestro libro mencionado, pp. 44-53), es «el más fehaciente documento del petrarquismo americano, único sin duda en el Virreinato del Perú» (p. 11). Y, creemos, de más perdurables valores poéticos, como lo hemos destacado en nuestro libro de 1966: «en los sonetos, sobre todo, [es] donde hay que hallar los altos valores de Dávalos de Figueroa, diestro versificador, lírico auténtico, primero y sin comparación entre los de su lugar y tiempo, en cantar las «cosas concernientes al amor», como dice en el Coloquio VI, y en poner su alma en la intensa y meditada confesión» (p. 75). Precisamente es este aspecto de la poesía del escijano el que privilegia, en su estudio, la profesora Colombí Monguió.

Es éste un libro que integra el saber erudito (como correspondía al estudiar uno de los autores más eruditos del petrarquismo hispánico) y la penetración crítica, basada en sólida doctrina de evaluación poética que, a la vez, integra, con incomparable saber, la teoría estética y las retóricas del renacimiento italiano con las más recientes aportaciones de la crítica textual difundida desde Francia, Ingla- 